\title{
Methodology Article: Can Ruminal Reducing Power Assessed in Batch Cultures be Comparable to in Vivo Measurements?
}

\author{
Christine Julien ${ }^{1,2,3 *}$, Jean-Philippe Marden4, Annabelle Troegeler-Meynadier, ${ }^{1,2,3}$, \\ Corine Bayourthe ${ }^{1,2,3}$ \\ ${ }^{1}$ INRA, UMR1388 Genetic, Physiology and Breeding System, Castanet-Tolosan, France \\ ${ }^{2}$ University of Toulouse INPT ENSAT, UMR1388 Genetic, Physiology and Breeding System, Castanet-Tolosan, \\ France \\ ${ }^{3}$ University of Toulouse INPT ENVT, UMR1388 Genetic, Physiology and Breeding System, Toulouse, France \\ ${ }^{4}$ Lesaffre Feed Additives, 282 Avenue de la Marne, Marcq-en-Baroeul, France \\ Email: ${ }^{*}$ c.julien@ensat.fr
}

Received 5 July 2014; revised 1 August 2014; accepted 8 August 2014

Copyright (C) 2014 by authors and Scientific Research Publishing Inc.

This work is licensed under the Creative Commons Attribution International License (CC BY).

http://creativecommons.org/licenses/by/4.0/

(c) (i) Open Access

\begin{abstract}
In ruminant field of digestive research, the appeal to methods of less invasive studies and reproducing the in vivo conditions is essential. The objective of the present study was to determine whether the conditions created with the proposed in vitro batch culture was an accurate reproduction of the physico-chemical and fermentative ruminal conditions observed in vivo. Two experiments were conducted to compare ruminal reducing power measured in vitro, i.e. in batch cultures or, in vivo i.e. in live animals: dairy cows at maintenance (Experiment 1) and lactating dairy cows (Experiment 2). In Experiment 1, at the beginning of incubation period, in vitro redox potential $\left(E_{h}\right), \mathrm{pH}$ and Clark's exponent $(\mathrm{rH})$ values were significantly higher than in vivo $(+42 \mathrm{mV},+0.25$ and +1.9 , respectively) whereas volatile fatty acids (VFA) contents were 2.6 fold lower on average. At the end of incubation, $\mathrm{E}_{h}$, $\mathrm{rH}$ values and VFA contents were similar between both methods whereas pH still remained different. In Experiment 2, at the beginning and at the end of incubation period, in vitro $\mathrm{E}_{h}, \mathrm{pH}$ and $\mathrm{rH}$ values differed significantly than in vivo. As a result, the in vitro method did not provide a tool to evaluate accurately the level of the reducing status of ruminal milieu compared with in vivo measurement. Nonetheless, it provided strong reducing conditions after $8 \mathrm{~h}$ of incubation with levels of $\mathrm{rH}$ relatively closed to those observed in vivo. In vitro batch culture could be a good alternative to in vivo trials for a screening approach from an ethic and economic point of view in ruminant field of research.
\end{abstract}

${ }^{*}$ Corresponding author.

How to cite this paper: Julien, C., et al. (2014) Methodology Article: Can Ruminal Reducing Power Assessed in Batch Cultures be Comparable to in Vivo Measurements? Journal of Analytical Sciences, Methods and Instrumentation, 4, 80-86. http://dx.doi.org/10.4236/jasmi.2014.43011 


\section{Keywords}

\section{Batch Cultures, Clark's Exponent, Redox Potential}

\section{Introduction}

Redox potential $\left(\mathbf{E}_{h}\right)$ is a physico-chemical measurement used to characterize an oxidizing or reducing milieu. It has already been applied to several organic media such as wine [1], soils [2] or milk-based products [3] to measure the electron availability within the system. Inside the rumen, $E_{h}$ values ranged generally between -220 and $-110 \mathrm{mV}$ and directly originated from the microbial activity [4]. In fact, electrons are involved in biochemical reactions implicated in ruminal metabolism. Baldwin and Emery [5] previously suggested a clear cut relationship between the metabolic rate of rumen microorganisms and ruminal $E_{h}$. As a matter of fact, ruminal $E_{h}$ is a mixed potential because of the strong fermentative activity involving numerous oxido-reducing couples. It reflects a weighted average of the potentials contributed by each of the redox couples as later mentioned by DeLaune and Reddy [2] in soil. In the rumen, some authors were interested in measuring $E_{h}$ to get a better insight in its factors of variation. So, ruminal $\mathrm{E}_{h}$ tended to be 45 to $100 \mathrm{mV}$ lower in ruminants fed a hay diet (70\% to $100 \%$ of forage) than in those fed a concentrated diet ( $40 \%$ to $80 \%$ of concentrate) [6]-[8]. In cows, Julien et al. [9] observed a relation between level of dry matter intake (DMI) and ruminal $E_{h}$ which could vary from -210 to $-165 \mathrm{mV}$, for a low (8 $\mathrm{kg}$ of DMI) and high $(21 \mathrm{~kg})$ level of DMI respectively. A more reducing ruminal environment was observed when ruminants were fed a yeast-supplemented diet: $-340 \mathrm{mV}$ vs. $-302 \mathrm{mV}$ in sheep [10] and $-149 \mathrm{mV}$ vs. $-115 \mathrm{mV}$ in cow [11]. Nonetheless, in vivo data remained scarce because of the difficulty of measurements in terms of anaerobiosis maintenance [12]. Furthermore, there are very few references regarding measurement of ruminal $E_{h}$ in vitro: values reached from -211 to $-233 \mathrm{mV}$ in an experiment conducted by Farghali and Iben [13] using Rusitec [14]. However, to our knowledge, no reference reported $E_{h}$ values in ruminal batch cultures. The $\mathrm{E}_{h}$ yields a primary indication of the reducing power in a given milieu and it is dependent upon the effects of $\mathrm{pH}$. Specifically, batch cultures are most of the time strongly $\mathrm{pH}$ buffered. To give a better appreciation of absolute reducing power in the milieu, Clark's Exponent (rH) is likely to be interesting to calculate because of integrating both $\mathrm{pH}$ and $\mathrm{E}_{h}$ values in Nernst's equation [15].

In ruminant research, the development and use of in vitro techniques to facilitate the study of ruminal microbial fermentation have been put forward in many studies. On the one hand, it deals with continuous or semi-continuous fermenters or the rumen simulating fermenter technique (Rusitec) developed by Czerkawski and Breckenridge [14] for several-days long incubations. On the other hand, it deals with in vitro batch mixed cultures for generally no more than 48-h long incubations. These different methods were permitted to focus on fermentations of different substrates or on the effect of abiotic or biotic factors such as dietary feed additives on rumen metabolism. Therefore, the objective of the present study was to determine whether the condition created with the proposed in vitro batch culture tracked over $8 \mathrm{~h}$ was an accurate reproduction of the physico-chemical and fermentative ruminal conditions observed in vivo.

\section{Materials and Methods}

\subsection{Animals and Diets}

The study was carried out on ruminally fistulated dairy cows with two levels of DMI. Four dry dairy cows at maintenance (Experiment 1) received $10 \mathrm{~kg}$ of DMI/d of a hay-based diet (91\% hay, 7\% soybean meal, and 2\% mineral vitamin mix). Four lactating dairy cows (Experiment 2) received $24 \mathrm{~kg}$ of DMI/d of two different diets only differing on the fermentative rate of degradation of the starch provided by the energetic concentrate: on a DM basis, $60 \%$ or $61 \%$ corn silage, $18 \%$ or $19 \%$ soybean meal, $21 \%$ ground wheat or $20 \%$ ground corn and $1 \%$ mineral vitamin mix, with respect to each diet. All diets consisted of total mixed ration (TMR) and were offered twice daily in equal portions at 900 and $1700 \mathrm{~h}$. For each experiment, animals were used for both in vivo measurements and as ruminal fluid donors for in vitro batch cultures, after a 3-wk adaptation period to their respective diets.

\subsection{In Vitro Experimental Procedure}

The in vitro batch cultures method was adapted from Troegeler-Meynadier et al. [16]. A total of 10 and 12 batch 
cultures per donor cow for Exp. 1 and Exp. 2, respectively, were made during 4 chosen experimental days. Each experimental day, approximately $2 \mathrm{~L}$ of ruminal fluid were withdrawn from donor cows before the morning meal (830 h). Ruminal fluid was strained through a metal sieve $(1.6 \mathrm{~mm}$ mesh) and transported to the laboratory by respecting temperature $\left(39^{\circ} \mathrm{C}\right)$ and anaerobic conditions. The ruminal fluid $(80 \mathrm{ml})$ was then poured in a $250-\mathrm{mL}$ Erlenmeyer flask with a same volume of a strictly anaerobic warmed $\left(39^{\circ} \mathrm{C}\right) 7-\mathrm{pH}$ buffer solution (containing $19.5 \mathrm{~g} / \mathrm{L} \mathrm{Na}{ }_{2} \mathrm{HPO}_{4} \cdot 12 \mathrm{H}_{2} \mathrm{O}, 9.24 \mathrm{~g} / \mathrm{L} \mathrm{NaHCO} 3,0.705 \mathrm{~g} / \mathrm{L} \mathrm{NaCl}, 0.675 \mathrm{~g} / \mathrm{L} \mathrm{KCl}, 0.108 \mathrm{~g} / \mathrm{L} \mathrm{CaCl}{ }_{2} \cdot 2 \mathrm{H}_{2} \mathrm{O}, 0.180 \mathrm{~g} / \mathrm{L}$ $\mathrm{MgSO}_{4} \cdot 7 \mathrm{H}_{2} \mathrm{O}$ and gazed with $\mathrm{CO}_{2}$ ) and dosed with approximately $3 \mathrm{~g}$ (on DM basis) of the TMR fed to the donor cows in respective experiment. For each trial, in vitro batch incubations with mixed rumen bacteria were tracked over $8 \mathrm{~h}$, in a water bath rotary shaker (Aquatron; Infors AG, 4103 Bottmingen, Germany) at $39^{\circ} \mathrm{C}$. After refilling flasks with $\mathrm{CO}_{2}$, they were closed with a special cap equipped with a tube that extremity dived into water, in order to clear out fermentation gas without entrance of oxygen, stirred at $130 \mathrm{rpm}$ and kept in the dark throughout the incubation. A non-incubated mix of ruminal fluid and 7-pH buffer was prepared as the same way but without any substrates. At the end of incubations, cultures were immediately placed into ice to stop further fermentation. Both the non-incubated mix and cultures were sampled with $10 \%$ of $\mathrm{HgCl}_{2}(2 \% \mathrm{wt} / \mathrm{vol})$ for subsequent VFA determination as described in Marden et al. [11]. Incubation flasks were equipped with a special cap permitting the introduction of two probes without compromising anaerobic conditions: a glass $\mathrm{pH}$ electrode (combined electrode with diaphragm DGSC; Metrohm, Herisau, Switzerland) and an $\mathrm{E}_{h}$ platinum electrode (Pt SC with Ag: AgCl as reference; Metrohm, Herisau, Switzerland). A third probe, a platinum thermo-electrode (Pt 1000), was dipped in a flask filled with water and placed inside the water bath to record temperature. Values of $\mathrm{pH}$ and $\mathrm{E}_{h}$ were recorded in each flask every hour during incubation period with a digital $\mathrm{pH}$ meter (Metrohm $713 \mathrm{CH}-9101$, Herisau, Switzerland) and $\mathrm{rH}$ was calculated: $\mathrm{rH}=\mathrm{E}_{h}(\mathrm{mV}) / 30+2 \mathrm{pH}$ [15].

\subsection{In Vitro Experimental Procedure}

The $\mathrm{pH}$ and $\mathrm{E}_{h}$ measurements were realized in vivo on the donor cows each hour from the morning meal (T0) to $8 \mathrm{~h}$ after (T8) by means of the method described by Julien et al. [8], during the day immediately following each day of in vitro cultures. Ruminal fluid was sampled with $10 \%$ of $\mathrm{HgCl}_{2}(2 \% \mathrm{wt} / \mathrm{vol})$ at $\mathrm{T} 0$ and $\mathrm{T} 8 \mathrm{for}$ subsequent volatile fatty acids (VFA) determination.

\subsection{Statistical Analysis}

For Exp. 1, pH, $\mathrm{E}_{h}, \mathrm{rH}$ and VFA contents determined at $\mathrm{T} 0$ and $\mathrm{T} 8$ were compared between methods (in vivo vs. in vitro) by ANOVA with GLM of SPSS (SPSS Version 13.0 for Windows, SPSS Inc., Chicago, Illinois, USA). For Exp. 2, pH, $\mathrm{E}_{h}, \mathrm{rH}$, and VFA contents determined at T0 and T8 were analyzed by ANOVA with GLM of SPSS, according to the following model: $Y_{i j k}=\mu+C_{i}+M_{j}+D_{k}+(M \times D)_{j k}+e_{i j k}$ where $Y_{i j k}$ is the dependent variable, $\mu$, the overall experimental mean, $C_{i}$, the mean effect of cow, $M_{j}$, the mean effect of the method, $D_{k}$, the mean effect of the diet and $e_{i j k}$ the random residual. Differences were then assessed by pairwise comparisons (Tukey's test). Mean values were reported with Standard Error of the Mean (SEM). Differences were considered significant at $P \leq 0.05$ and trends were discussed at $0.05<P \leq 0.15$.

\section{Results}

\subsection{Experiment 1}

The $\mathrm{E}_{h}, \mathrm{pH}$ and $\mathrm{rH}$ values recorded in vitro at the beginning of incubation time were significantly higher than the values recorded in vivo: $+42 \mathrm{mV},+0.25 \mathrm{pH}$-units and +1.9 , respectively (Table 1 ).

At the end of incubation, $\mathrm{pH}$ values recorded in vitro remained different $(P<0.001)$ than in vivo measurements but both $E_{h}$ values and $\mathrm{rH}$ did not differ averaging $-189 \mathrm{mV}$ and 7.1, respectively. Total VFA, acetate (C2), propionate (C3) and butyrate (C4) contents observed in vitro were on average 2.6 and 1.2 fold significantly lower than in vivo at the beginning and at the end of incubation, respectively.

\subsection{Experiment 2}

For 0-h incubations, $\mathrm{E}_{h}$ and $\mathrm{pH}$ values differed significantly between experimental methods but not within diet: $-91 \mathrm{mV}$ and 6.81 on average in vitro vs. $-179 \mathrm{mV}$ and 6.53 on average in vivo (Table 2). 
Table 1. Comparison of physico-chemical and fermentative parameters observed in vitro and in vivo in Experiment 1.

\begin{tabular}{|c|c|c|c|c|c|}
\hline & & In vitro & In vivo & SEM & $P$-value \\
\hline \multirow[t]{2}{*}{$\mathrm{E}_{\mathrm{h}}{ }^{1}, \mathrm{mV}$} & T0 & -115 & -157 & 7.34 & 0.002 \\
\hline & T8 & -189 & -189 & 4.48 & 0.996 \\
\hline \multirow[t]{2}{*}{$\mathrm{pH}$} & T0 & 6.91 & 6.66 & 0.03 & $<0.0001$ \\
\hline & $\mathrm{T} 8$ & 6.82 & 6.62 & 0.03 & $<0.0001$ \\
\hline \multirow[t]{2}{*}{$\mathrm{rH}^{2}$} & T0 & 10.0 & 8.1 & 0.28 & $<0.0001$ \\
\hline & T8 & 7.3 & 6.9 & 0.17 & 0.235 \\
\hline \multirow[t]{2}{*}{ Total VFA, mM } & T0 & 27.9 & 71.5 & 4.51 & $<0.0001$ \\
\hline & $\mathrm{T} 8$ & 54.9 & 65.0 & 1.83 & 0.001 \\
\hline \multirow[t]{2}{*}{ Acetate, mM } & T0 & 20.2 & 51.8 & 3.26 & $<0.0001$ \\
\hline & T8 & 38.1 & 46.5 & 1.32 & $<0.0001$ \\
\hline \multirow[t]{2}{*}{ Propionate, mM } & T0 & 4.8 & 12.5 & 0.83 & $<0.0001$ \\
\hline & $\mathrm{T} 8$ & 10.4 & 11.4 & 0.34 & 0.049 \\
\hline \multirow[t]{2}{*}{ Butyrate, mM } & T0 & 2.0 & 5.2 & 0.33 & $<0.0001$ \\
\hline & T8 & 4.6 & 5.6 & 0.17 & 0.001 \\
\hline
\end{tabular}

${ }^{1} \mathrm{E}_{h}=$ redox potential.; ${ }^{2} \mathrm{rH}=\mathrm{E}_{h}(\mathrm{mV}) / 30+2 \mathrm{pH}$ [15]. Measurements were made from the morning meal (T0) to $8 \mathrm{~h}$ after (T8).

Table 2. Comparison of physico-chemical and fermentative parameters observed in vitro and in vivo in Experiment 2.

\begin{tabular}{|c|c|c|c|c|c|c|c|c|c|}
\hline & \multicolumn{5}{|c|}{ Treatments $^{1}$} & \multirow[b]{3}{*}{ SEM } & \multicolumn{3}{|c|}{$P$-value ${ }^{2}$} \\
\hline & & \multicolumn{2}{|c|}{ In vitro } & \multicolumn{2}{|c|}{ In vivo } & & \multirow[b]{2}{*}{ M } & \multirow[b]{2}{*}{$\mathrm{D}$} & \multirow[b]{2}{*}{$\mathrm{M} \times \mathrm{D}$} \\
\hline & & Wheat & Corn & Wheat & Corn & & & & \\
\hline \multirow[t]{2}{*}{$\mathrm{E}_{h}{ }^{3}, \mathrm{mV}$} & T0 & -82 & -99 & -186 & -171 & 8.97 & $<0.0001$ & 0.845 & 0.125 \\
\hline & $\mathrm{T} 8$ & -182 & -190 & -172 & -164 & 3.87 & 0.038 & 0.871 & 0.188 \\
\hline \multirow[t]{2}{*}{$\mathrm{pH}$} & $\mathrm{T} 0$ & 6.78 & 6.84 & 6.47 & 6.59 & 0.037 & $<0.0001$ & 0.143 & 0.651 \\
\hline & T8 & 6.23 & 6.42 & 5.75 & 5.93 & 0.062 & $<0.0001$ & 0.031 & 0.877 \\
\hline \multirow[t]{2}{*}{$\mathrm{rH}^{4}$} & $\mathrm{~T} 0$ & 10.8 & 10.4 & 6.8 & 7.5 & 0.34 & $<0.0001$ & 0.768 & 0.089 \\
\hline & $\mathrm{T} 8$ & 6.5 & 6.6 & 5.7 & 6.4 & 0.12 & 0.028 & 0.098 & 0.235 \\
\hline \multirow[t]{2}{*}{ Total VFA, mM } & $\mathrm{T} 0$ & 42.8 & 46.5 & 80.4 & 83.1 & 2.83 & $<0.0001$ & 0.526 & 0.868 \\
\hline & $\mathrm{T} 8$ & 115.4 & 108.8 & 114.3 & 108.7 & 1.77 & 0.907 & 0.216 & 0.916 \\
\hline \multirow[t]{2}{*}{ Acetate, mM } & $\mathrm{T} 0$ & 25.1 & 29.6 & 47.3 & 52.2 & 1.78 & $<0.0001$ & 0.075 & 0.948 \\
\hline & $\mathrm{T} 8$ & 64.1 & 64.3 & 63.4 & 65.4 & 1.09 & 0.945 & 0.704 & 0.739 \\
\hline \multirow[t]{2}{*}{ Propionate, mM } & $\mathrm{T} 0$ & 10.5 & 8.5 & 20.0 & 16.7 & 0.92 & $<0.0001$ & 0.123 & 0.758 \\
\hline & $\mathrm{T} 8$ & 28.3 & 20.5 & 30.6 & 23.6 & 0.91 & 0.100 & $<0.0001$ & 0.837 \\
\hline \multirow[t]{2}{*}{ Butyrate, mM } & $\mathrm{T} 0$ & 4.8 & 6.0 & 9.1 & 10.4 & 0.46 & 0.002 & 0.331 & 0.981 \\
\hline & $\mathrm{T} 8$ & 16.0 & 17.8 & 14.8 & 14.8 & 0.40 & 0.038 & 0.363 & 0.376 \\
\hline
\end{tabular}

${ }^{1}$ Wheat $=$ wheat diet; Corn = corn diet; ${ }^{2} \mathrm{M}=$ method; $\mathrm{D}=$ diet; $\mathrm{M} \times \mathrm{D}=$ method $\times$ diet interaction effect; ${ }^{3} \mathrm{E}_{h}=$ redox potential; ${ }^{4} \mathrm{rH}=\mathrm{E}_{h}(\mathrm{mV}) / 30+$ ${ }^{2} \mathrm{pH}$ [15]. Measurements were made from the morning meal (T0) to $8 \mathrm{~h}$ after (T8). 
For 8 h-incubations, $\mathrm{E}_{h}$ and $\mathrm{pH}$ values recorded in vitro and in vivo remained significantly different, but were numerically closer than at T0. The $\mathrm{pH}$ values were higher $(P=0.031)$ considering corn than wheat $(6.18$ and 5.99 on average, respectively). Regarding $\mathrm{rH}$ values at $\mathrm{T} 0$, there was a trend $(P=0.089)$ to an interaction between experimental method and diet. At T8, rH values were still higher in vitro than in vivo, but values were numerically closer than at T0. They tended to differ $(P=0.098)$ with diet without any interaction between the two tested factors. Whatever was the diet, total VFA, C2, C3 and C4 contents determined in vitro were lower ( $P \leq$ 0.002) than in vivo at T0 : 44.7 vs. $81.8 \mathrm{mM}, 27.4$ vs. $49.8 \mathrm{mM}, 9.5$ vs. $18.4 \mathrm{mM}$ and 5.4 vs. $9.8 \mathrm{mM}$ on average, respectively. At T8, no difference was observed between experimental methods excepted for C4 content which was higher $(P=0.038)$ in vitro than in vivo whatever was the diet. At T8, the C3 content was significantly higher for wheat than for corn for both methods ( $+7.5 \mathrm{mM}$ on average).

\section{Discussion}

The objectives of this study were to evaluate the relevancy of ruminal $E_{h}$ measurement in ruminal batch cultures, using an in vivo model as a reference, and to ascertain that this in vitro method would permit obtaining and maintaining an anaerobic environment corresponding to the common strong reducing conditions in rumen of dairy cows.

In vitro, $\mathrm{pH}$ was largely influenced by the strong buffering conditions i.e. the use of the 7-pH buffer with a rumen fluid to 7-pH buffer ratio of 50/50, which logically conducted to a higher $\mathrm{pH}$ in vitro than in vivo (Table 1 and Table 2). Given that the true reducing power is dependent on $\mathrm{pH}$, there seemed requisite to correct $\mathrm{E}_{h}$ values by $\mathrm{pH}$ and so evaluating the true reducing power of the milieu by means of Clark's exponent calculation. Actually, regarding both experiments, 0 h-incubations milieu was much less reducing in vitro than in vivo because of ruminal fluid contact with air outside the rumen leading to a drastic increase of $\mathrm{E}_{h}$ and $\mathrm{rH}$ values. After $8 \mathrm{~h}$ of incubation, both methods led to similar $\mathrm{E}_{h}$ and $\mathrm{rH}$ values for hay-based diet fed to cows at maintenance (Exp. 1) while, from a statistical point of view, $\mathrm{E}_{h}$ and $\mathrm{rH}$ values still differed for concentrated diets (Exp. 2). Those latter results questioned the level of accuracy of the reproduction of the ruminal redox status. From our point of view, the difference observed was in small part explained by outflow and turn over limits of the fermentative milieu in such closed incubated systems. Regarding the reducing power of the milieu expressed in terms of rH in Exp. 2, the significant difference between in vitro and in vivo measurement conditions undoubtedly resulted from the higher difference observed between in vivo and in vitro $\mathrm{pH}$ values recorded at $8 \mathrm{~h}(0.49 \mathrm{pH}$-units, on average for both diets) than in Exp. 1 (0.20 pH-units). Those observations suggested that the commonly used 7-pH-buffer for batch cultures was not completely adapted for all batch cultures. More specifically, in Exp. 2, experimental conditions clearly led to an in vitro reducing milieu but presenting a significantly different reducing power than in vivo ruminal milieu. Unfortunately, references regarding in vitro ruminal oxydo-reducing conditions are very scarce. To our knowledge, no reference reported $\mathrm{E}_{h}$ values in ruminal batch cultures and none of the authors tackled the question of the oxydo-reducing status of in vitro cultures by means of rH calculation. But, obviously, the present study tackle the fact that from a technical and biological point of view, our in vitro experimental method offered indeed a very reducing environment which could be very close to the rumen confirming the preliminary observations of Julien et al. [17].

For both experiments, fermentative parameters at T0 definitely differ between methods: dilution of ruminal fluid with $\mathrm{pH}$ buffer explains in large part the difference in VFA contents values but filtration should also be taken into account. Actually, in vitro inocula containing only strained ruminal fluid yields slower digestion and VFA patterns than in vitro inocula containing whole ruminal contents more similar to in vivo [18]. After $8 \mathrm{~h}$, the fermentative conditions remained different between the two methods in Exp. 1. The lower VFA contents in cultures than in rumen could be explained by the low energy content of the fermentative substrates containing most part of hay. This assumption was corroborated by results obtained in Exp. 2 where cows received a concentrated diet: in vivo fermentative conditions at T8 were similar to in vitro conditions where ruminal fluid, was incubated with a similar high-energy content substrate. Additionally, $\mathrm{pH}$ decrease from 0 to $2 \mathrm{~h}$ of incubation was 0.07 $\mathrm{pH}$-units in experiment 1 whereas it represented $0.16 \mathrm{pH}$-units on average in experiment 2, putting forward that fermentative activity of ruminal fluid used for batch cultures presented a delayed phase more important for hay-based diet than for concentrated diets. It probably explains that fermentative parameters still differed at $8 \mathrm{~h}$ in experiment. 1 and were similar in Exp. 2. Additionally, $\mathrm{E}_{h}$ value decreased sharply the first hour of in vitro incubation in both experiments ( $-74 \mathrm{mV}$ on average) compared to in vivo ( $-4 \mathrm{mV}$ on average). This result demon- 
strated that, after an exogenous perturbation, ruminal microbiota has a proper capacity to rapidly restore ruminal reducing conditions resulting requisite for ruminal metabolism.

To go a step further, on cows fed high-concentrated diets (Exp. 2), at $8 \mathrm{~h}$, rH values differed significantly with methods but a diet effect tended ( $P=0.098$ ) to appear whatever the method used ( $M \times D, P=0.235$ ). So that, for high concentrated-diets, the present in vitro method permitted to obtain reducing conditions in the batch cultures but did not provide a tool to evaluate accurately the level of the reducing status of ruminal milieu compared with live animals. Nevertheless, it seems to also provide a good way to explore the relative effect of an exogenous variation factor such as starch fermentative rate on ruminal reducing conditions.

\section{Conclusion}

As expected, the present study visibly is put forward that our in vitro batch culture method is not accurate enough to determine ruminal $\mathrm{pH}$ and $\mathrm{E}_{h}$ absolute values induced by the diet fed to the cows: in vivo measurements have to be realized. Nonetheless, the main objective of the study was reached: it showed that the in vitro method provided strong reducing conditions after $8 \mathrm{~h}$ of incubation with levels of $\mathrm{rH}$ relatively closed to those observed in vivo. It appears to be a useful technique for potentially testing the effect of exogenous substances and determining relative differences in ruminal-reducing status. It resulted that it could be a good alternative to in vivo trials for a screening approach from an ethic and economic point of view in ruminant field of research.

\section{Acknowledgements}

This work was funded by a grant from Lesaffre Feed Additives. The authors gratefully acknowledge Dr. Eric Auclair and Nina Munsters. The authors gratefully acknowledge the staff at the experimental station and particularly Brigitte Gestes, for their technical assistance.

\section{References}

[1] Tomlinson, J.W. and Kilmartin, P.A. (1997) Measurement of the Redox Potential of Wine. Journal of Applied Electrochemistry, 27, 1125-1134. http://dx.doi.org/10.1023/A:1018407230924

[2] De Laune, R.D. and Reddy, K.R. (2005) Redox Potential. In: Hillel, D., Ed., Encyclopedia of Soils in the Environment, Academic Press, Elsewier Ltd., 366-371.

[3] Brasca, M., Morandi, S., Lodi, R. and Tamburini, A. (2007) Redox Potential to Discriminate among Species of Lactic Acid Bacteria. Journal of Applied Microbiology, 103, 1516-1524. http://dx.doi.org/10.1111/j.1365-2672.2007.03379.x

[4] Julien, C., Marden, J.P., Moncoulon, R. and Bayourthe, C. (2010) Redox Potential Measurement: A New Way to Explore Ruminal Metabolism. Journal of Animal Science, 88, 578.

[5] Baldwin, B.L. and Emery, R.S. (1960) Investigation of the Oxidation-Reduction Potential of Rumen Contents. Journal of Dairy Science, 43, 506-511. http://dx.doi.org/10.3168/jds.S0022-0302(60)90193-4

[6] Barry, T.N., Thompson, A. and Armstrong, D.G. (1977) Rumen Fermentation Studies on Two Constrasting Diets. 1. Some Characteristics of the in Vivo Fermentation, with Special Reference to the Composition of the Gas Phase, Oxidation/Reduction State and Volatile Fatty Acid Proportions. Journal of Agricultural Science, 89, 183-195. http://dx.doi.org/10.1017/S0021859600027362

[7] Marounek, M., Bartos, S. and Kalachnyuk, G.I. (1982) Dynamics of the Redox Popential and rH of the Rumen Fluid of goats. Physiologia Bohemoslova, 31, 369-374.

[8] Julien, C., Marden, J.P., Bonnefont, C., Moncoulon, R., Auclair, E., Monteils, V. and Bayourthe, C. (2010) Effects of Varying Proportions of Concentrates on Ruminal-Reducing Power and Bacterial Community Structure in Dry Dairy Cows fed Hay-Based Diets. Animal, 4, 1641-1646. http://dx.doi.org/10.1017/S1751731110000972

[9] Julien, C., Marden, J.P., Moncoulon, R., Auclair, E. and Bayourthe, C. (2010) Ruminal Redox Potential in Dairy Cows Regarding Diet Composition and Live Yeast Supplementation: A Modelling Approach. Proceedings of the 3rd International EAAP Symposium on Energy and Protein Metabolism and Nutrition, Parma, 6-10 September 2010, 551.

[10] Mathieu, F., Jouany, J.P., Senaud, J., Bohatier, J., Bertin, G. and Mercier, M. (1996) The Effect of Saccharomyces cerevisiae and Aspergillus oryzae on Fermentations in the Rumen of Faunated and Defaunated Sheep: Protozoal and Probiotics Interactions. Reproduction Nutrition Développement, 36, 271-287. http://dx.doi.org/10.1051/rnd:19960305

[11] Marden, J.P., Julien, C., Monteils, V., Auclair, E., Moncoulon, R. and Bayourthe, C. (2008) How Does Live Yeast Differ from Sodium Bicarbonate to Stabilize Ruminal pH in High-Yielding Dairy Cows? Journal of Dairy Science, 91, 3528-3535. http://dx.doi.org/10.3168/jds.2007-0889 
[12] Marden, J.P., Bayourthe, C., Enjalbert, F. and Moncoulon, R. (2005) A New Device for Measuring Kinetics of Ruminal pH and Redox Potential in Dairy Cows. Journal of Dairy Science, 88, 277-281. http://dx.doi.org/10.3168/jds.S0022-0302(05)72685-0

[13] Farghali, M.M. and Iben, C. (2009) Effect of Heat Treatment of Canola Seed and Canola Meal on Rumen Fermentation in Vitro. Proceedings of the 13rd Congress of the ESVCN, Oristano, 15-17 October 2009, 132.

[14] Czerkawski, J.W. and Breckenridge, G. (1977) Design and Development of a Long-Term Rumen Stimulation Technique (Rusitec). British Journal of Nutrition, 38, 371-384. http://dx.doi.org/10.1079/BJN19770102

[15] Marounek, M., Roubal, P. and Bartos, S. (1987) The Redox Potential, rH and pH Values in the Gastrointestinal Tract of Small Ruminants. Physiologica Bohemoslova, 36, 71-73.

[16] Troegeler-Meynadier, A., Nicot, M.C., Bayourthe, C., Moncoulon, R. and Enjalbert, F. (2003) Effects of pH and Concentrations of Linoleic and Linolenic Acids on Extent and Intermediates of Ruminal Biohydrogenation in Vitro. Journal of Dairy Science, 86, 4054-4063. http://dx.doi.org/10.3168/jds.S0022-0302(03)74017-X

[17] Julien, C., Troegeler-Meynadier, A., Marden, J.P., Enjalbert, F. and Bayourthe, C. (2009) In Vivo and in Vitro Measurements of Ruminal Redox Potential: A Comparative Study. Journal of Animal Science, 87, 477.

[18] Craig, W.M., Hong, B.J., Broderick, G.A. and Bula, R.J. (1984) In Vitro Inoculum Enriched with Particle-Associated Microorganisms for Determining Rates of Fiber Digestion and Protein Degradation. Journal of Dairy Science, 67, 2902-2909. http://dx.doi.org/10.3168/jds.S0022-0302(84)81653-7 
Scientific Research Publishing (SCIRP) is one of the largest Open Access journal publishers. It is currently publishing more than 200 open access, online, peer-reviewed journals covering a wide range of academic disciplines. SCIRP serves the worldwide academic communities and contributes to the progress and application of science with its publication.

Other selected journals from SCIRP are listed as below. Submit your manuscript to us via either submit@scirp.org or Online Submission Portal.
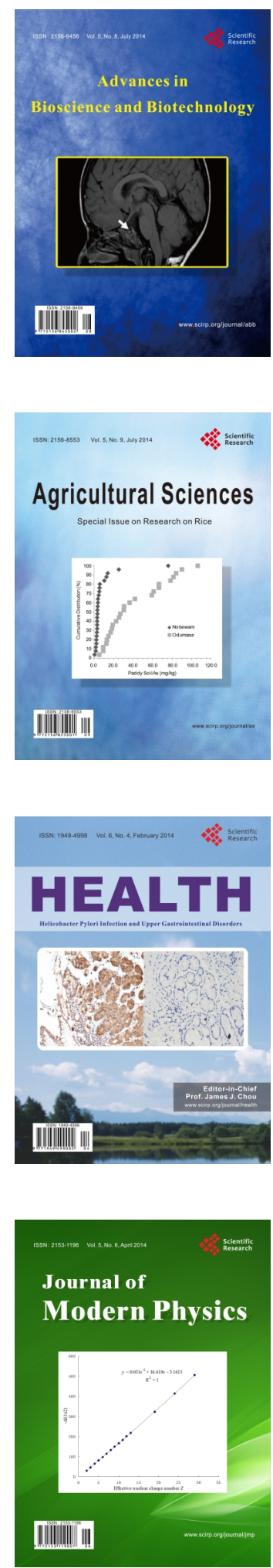
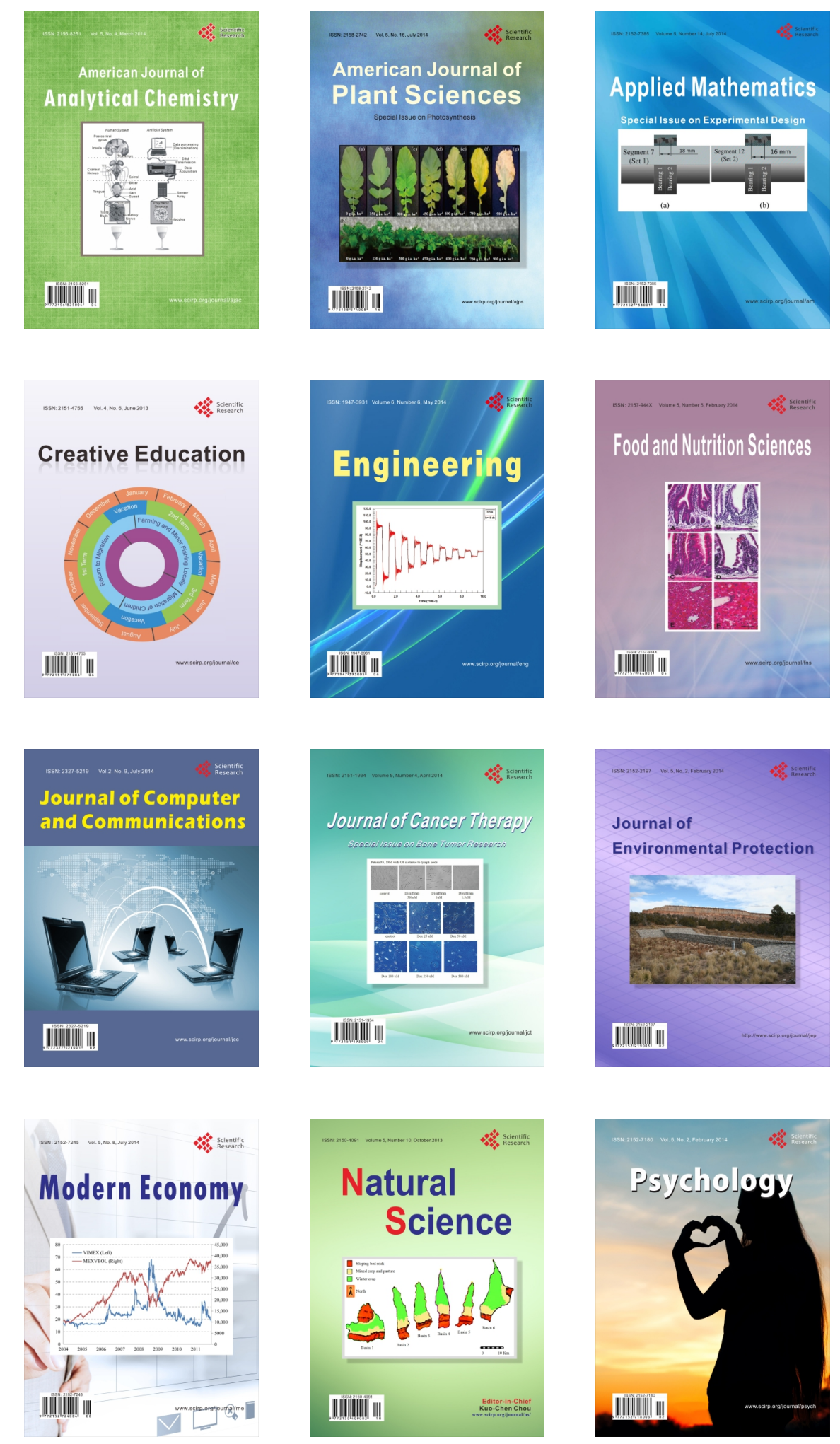